\section{Quality of life in chronic disease patients}

\author{
Kalliopi Megari \\ School of Psychology, Aristotle \\ University of Thessaloniki, Greece
}

\section{Abstract}

During the past decades there was an increasing predominance of chronic disorders, with a large number of people living with chronic diseases that can adversely affect their quality of life. The aim of the present paper is to study quality of life and especially Healthrelated quality of life (HRQoL) in chronic diseases. HRQOL is a multidimensional construct that consists of at least three broad domains physical, psychological, and social functioning - that are affected by one's disease and/or treatment. HRQoL is usually measured in chronic conditions and is frequently impaired to a great extent. In addition, factors that are associated with good and poor HRQoL, as well as HRQoL assessment will be discussed. The estimation of the relative impact of chronic diseases on HRQoL is necessary in order to better plan and distribute health care resources aiming at a better HRQoL.

[ All the people perceive the concept of living good or being well, that is the same as being happy». (Aristotle. 384-322 BC. Ethica Nichomachea)]

\section{Quality of life}

The World Health Organization (WHO) defines health as not merely the absence of disease or infirmity, but a state of complete psychical, mental and social well being. ${ }^{1}$ The definition of Quality of Life $(\mathrm{QoL})$ is more complex. According to WHO, QoL is defined as individuals' perceptions of their position in life in the context of the culture and value systems in which they live and in relation to their goals, expectations, standards and concerns. ${ }^{2}$ QoL is the feeling of overall life satisfaction, as determined by the mentally alert individual whose life is being evaluated. ${ }^{3}$ This appraisal is subjective, and encompasses all domains of life, including elements of a biopsychosocialspiritual model. ${ }^{4}$ The use of the term subjective has different connotations to different people and can be perceived as not reliable because it is not objective. Subjective can be synonymous with self-perceived meaning that a person primarily gives information about himself.
Other definitions of QoL suggest that it is $a$ global personal assessment of a single dimension which may be causally responsive to a variety of other distinct dimensions: it is a unidimensional concept with multiple causes. ${ }^{5}$ Therefore, it encompasses the entire range of human experience, states, perceptions and spheres of thought concerning the life of an individual or a community. Both objective and subjective QoL can include cultural, physical, psychological, interpersonal, spiritual, financial, political, temporal and philosophical dimensions. QoL implies a judgment of value placed on the experience of communities, groups such as families or individuals. ${ }^{6}$

Finally, it is suggested that QoL can theoretically encompass a wide ranging array of domains and components. These involve functional ability including role functioning (functional ability in different roles like in physical activities and achievement beliefs), the degree and quality of social interaction, psychological well-being, somatic sensations, happiness, life situations, life satisfaction and need for satisfaction. ${ }^{7}$ It also reflects life experiences', significant life events and the current phase of the life and the factors defining QoL in this respect further include sex, socioeconomic status, age and generation. ${ }^{8} \mathrm{QoL}$ is thus a complex collection of interacting objective and subjective dimensions: encompasses the individual's perspective, is assessed through the eye of the experiencer, ${ }^{9}$ and is likely to be mediated by cognitive factors. ${ }^{7}$

\section{Health related quality of life}

Patrick and Erickson (1993) define healthrelated quality of life $(\mathrm{HRQOL})$ as the value assigned to duration of life as modified by the impairments, functional states, perceptions and social opportunities that are influenced by disease, injury, treatment or policy. ${ }^{6}$ A main topic in HRQoL includes patients' appraisal of their current level of functioning, as well as satisfaction with it, compared to what they believe to be ideal. An important aspect in HRQoL study is how the manifestation of an illness or treatment is experienced by an individual. Patients' heath status assessment includes personal experiences which are affected by health care interventions as well as changes over time with a chronic disease and no particular treatment. For example, evaluation of HRQoL over time after disease such as stroke, for individuals who have completed treatment and rehabilitation and are living with the effects of this disease. $^{10}$

It is generally accepted that HRQOL is a multidimensional construct that consists of at least three broad domains - physical, psychological, and social functioning - that are affect-
Correspondence: Kalliopi Megari, Aristotle University of Thessaloniki, 54124 Thessaloniki, Greece.

E-mail: kmegari@psy.auth.gr

Key words: health related quality of life, health status, chronic disease, quality of life, patients.

Conflict of interests: the authors declares no potential conflict of interests.

Received for publication: 13 January 2013.

Revision received: 1 March 2013.

Accepted for publication: 2 March 2013.

This work is licensed under a Creative Commons Attribution NonCommercial 3.0 License (CC BYNC 3.0).

CC Copyright K. Megari et al., 2013

Licensee PAGEPress, Italy

Health Psychology Research 2013; 1:e27

doi:10.4082/hpr.2013.e27

ed by one's disease and/or treatment. Physical functioning is usually defined as the ability to perform a range of activities of daily living, as well as physical symptoms resulting from the disease itself or from treatment. Psychological functioning ranges from severe psychological distress to a positive sense of well-being and may also encompass cognitive functioning. Social functioning refers to quantitative and qualitative aspects of social relationships and interactions and societal integration. ${ }^{I I}$

A model of HRQoL might lead to a better explanation of the previous statements. Wilson \& Cleary (1995) describe a conceptual model of HRQoL that provides a theoretical approach to conceptualizing $\mathrm{HRQOL}$ as a multidimensional construct and integrates biological and psychological aspects of health outcomes. ${ }^{12}$ This model consists of five different levels namely, physiological factors, symptom status, functional health, general health perceptions and overall QoL. It has been widely applied to different populations, including patients with cancer, arthritis, Parkinson's disease and HIV. It is indicated that symptom status, functional health, general health perceptions, and overall QoL are dimensions of HRQoL (Figure 1). ${ }^{12}$

Figure 1 depicts the hypothesized linkages between the dimensions. The model suggests that physiological variables influence symptom status, symptom status influences functional health, functional health influences general health perceptions and general health perceptions influence overall QoL. The evaluation of physiological variables focuses on cells, organs, and organ systems, though the assessment of symptom status shifts to the organism as a whole. ${ }^{12}$ Functional health is defined as the ability of an individual to perform and 
adapt to one's environment, measured both objectively and subjectively over a given period. General health perceptions reflect an integration of all health concepts previously reviewed, additional with mental health and they are by definition subjective ratings. Although health perceptions are personal beliefs, overall QoL has been described as the discrepancy between a person's expectations or hopes and his present experiences. ${ }^{13}$ Wilson \& Cleary model was later revised by investigators Ferrans, Zerwic, Wilbur \& Larson (2005). The revised model was developed in order to explain the relationships of clinical variables that relate to QoL by linking individual characteristics with environmental characteristics. ${ }^{14}$

In parallel, a number of studies of HRQoL have been conducted in health care literature to test these findings. Zautra \& Hempel (1984) reviewed many studies of health and reported that, overall, high correlations were found between self-reported health status and indicators of well-being, although this association does not indicate the direction of causality. ${ }^{15}$ Good levels of physical and mental functioning and general health status have long been associated with perceived well-being, morale and overall QoL. ${ }^{16}$

On the other hand, Bowling et al. focused on the concept that HRQoL has been based on a model of illness-health and dependency. They have also focused on the impact of illnesshealth status and disease on, and measurement of, physical and mental disability and impaired role functioning. The emphasis has been on (dys) functional status. Functional status is the degree to which a person is able to perform socially allocated roles free of physical or mental health related limitations. ${ }^{17}$ It emphasizes the ability to perform activities of daily living and mobility (e.g. self-care), instrumental daily living (e.g. housework) and more recently, social role obligations. The aim of measurement has usually been to track the speed of return to normal activities, whenever this is obtainable. 17 There are many situations where it is not expected a return to normal activities, especially with a chronic, progressive condition. The aim, however, may be concerned in observing changes in HRQoL over time.

Broader models of health are generally based on the WHO's (1954) earlier definition of health, with broader measures of health outcomes which incorporate social, physical and psychological well-being and positive health, alongside self-rated health status, rather traditional indicators. These models are based on prevalence of risk conditions (e.g. obesity) selected chronic conditions (e.g. asthma, diabetes) and mortality rates (all causes, specific causes). ${ }^{6}$ They emphasise not just the absence of disease and disability, but to a number of

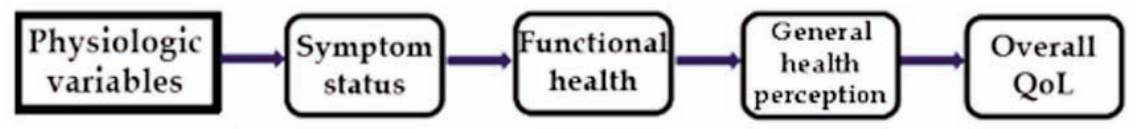

Figure 1. The pathway in the Wilson and Cleary (1995) HRQOL conceptual model.

reasons: completeness, efficiency of mind and body, the ability to cope with stressful situations, social support and psychological wellbeing, including life satisfaction, physical fitness and health. ${ }^{6}$

In conclusion HRQoL as a multidimensional construct has a lot of research that focuses on different dimensions. Wilson \& Clary model is a model that integrates biological and psychological aspects of health outcomes. Other researchers emphasize on the absence of health and the ability of someone to perform activities of daily living. The point is that all these views may seem different, but they tend to focus on the dimensions of HRQoL and provide us with very useful findings.

\section{Health related quality of life in chronic diseases}

During the past decades there was an increasing predominance of chronic disorders, as a result of improved living conditions, better prevention, infectious diseases management, medical technological improvements and overall aging of the population. Therefore, an increasing number of people live with chronic diseases that can adversely affect their HRQoL. In general, chronic diseases are slow in progression, long in duration, and they require medical treatment. The majority of chronic diseases hold the potential to worsen the overall health of patients by limiting their capacity to live well, limit the functional status, productivity and HRQoL and are a major contributor to health care costs. ${ }^{18}$ Among these diseases are cancer, heart diseases, stroke, diabetes, HIV, bowel diseases, renal disease and diseases of central nervous system.

Devins et al. (1983), claim that chronic disease disrupts an individual's life and that this disruption may be interpreted in terms of its impact on well-being, or QoL. Psychosocial well-being is compromised by two limitations: by reducing positively reinforcing outcomes of participating in valued activities and feelings of personal control and by limiting the ability to obtain positive outcomes or avoid negative ones. They have further suggested that this impact can be assessed in terms of QoL domains. ${ }^{18}$

The literature in health psychology general- ly supports the hypothesis that most patients do compare themselves with those patients who are better off (upward comparisons). ${ }^{19}$ This positive focus on limitations may be responsible for the better psychological adjustment to illness among this group, in comparison with those who make downward comparisons. Patients tend to make downward comparisons of themselves with patients worse off with them, only when experiencing difficulties and make upward comparisons with people healthier than themselves when setting standards for their recovery. ${ }^{20}$

In the context of chronic diseases study, HRQoL is studied as a primary or secondary outcome. HRQoL is an important measure to evaluate the impact of a disease and the effects of medical intervention, thus, an improvement in HRQoL is considered to be an essential primary outcome and determinant of therapeutic benefit. ${ }^{10}$ While, it is found more usually to be the secondary outcome that provides the researchers with hypothesis-generating data. In some cases the outcomes of interest may involve only certain domains such as physical functioning or emotional functioning. Information on the impact of chronic diseases on HRQoL can make health services more patient-centred. ${ }^{10}$

Conclusively, as the number of people with chronic diseases is increasing it is necessary for them to gain an optimal HRQoL. To achieve this, a study of HRQoL is used to evaluate the impact of a disease and the effects of medical interventions. This study would provide information so that the patients' voice should mainly be considered.

\section{Health related quality of life assessment in chronic disease}

HRQoL can be assessed either by interview or questionnaire. Interview methods use openended or semi-structured methods, are useful for initial creation of items to be used subsequently in questionnaires to discover issues and to describe the experiences of the patients. $^{10}$

As regards questionnaires two main types are used: i) generic HRQoL questionnaires, which are used to evaluate HRQoL in different populations and ii) specific HRQoL question- 
naires, which are used to evaluate HRQoL in patients with specific conditions and are claimed to be more responsive, as they include items relevant to the designated patient population. Both generic and specific instruments have pros and cons and must be estimated within the context of the particular study. ${ }^{10}$

Generic instruments allow comparisons between across conditions and interventions, but usually do not focus on a specific intervention adequately. These measures can provide population norms of healthy HRQoL to which HRQoL in disease states can be compared and admit comparisons across different diseases and conditions and across interventions. Generic health status measures differentiate groups on important dimensions of overall health and functioning and can also be more sensitive to comorbid conditions. ${ }^{10}$ They are also useful for policy analysis and health care decision making and because of their broader range of assessment they may yield unexpected findings (regarding comparisons to different groups of health conditions). ${ }^{5}$ This means that they are used to assess the efficiency of the chosen treatment by considering the patients' perspectives. It becomes necessary to have assessment methods that are able to verify the fact that although the treatment used does not completely restore health, it at least restores QoL to acceptable levels.

On the other hand, specific instruments are usually more comprehensive and provide greater precision and sensitivity to clinically important changes that might be missed by broader assessment approaches. In addition, they are more responsive to change, but are not inclusive and may not be available for certain populations, since such measures are designed to access specific patient population and disease states. ${ }^{10}$ There are instruments designed to assess specific conditions or symptoms, such as pain, fatigue and depression that may occur in many different kinds of diseases. Some measures assess those symptoms and concerns that occur in association with particular treatments, but which may be common to several diseases. ${ }^{10}$ Specific measures have the advantage of being more closely related to physical findings and disease correlates, but their major disadvantage is that they are often limited to particular populations or interventions. ${ }^{10}$

In parallel, there are some characteristics for desirable measures. The data must be based on patients' opinion, changes in priorities with increasing age and understandable language must be used. They must have reliability, validity (content validity), sensitivity to change/responsiveness, if the measure is to be used to evaluate change over time and provide quantifiable results with clinical and statistical significance. Additionally, they should be mul- tidimensional, attainable to patients, being short and usable in a busy clinical setting. 10

Finally, some of the measures that are commonly used in studies of chronic disease are the Medical Outcomes Study 36-Item ShortForm Health Survey (SF-36), ${ }^{21}$ the Nottingham Health Profile (NHP) and the EuroQol (EQ5D). ${ }^{22,23}$ These instruments are translated in many languages and are used in many countries. An example of specific instrument is the Functional Assessment of Cancer TherapyGeneral (FACT-G) that can be used as generic by deleting those questions that ask about one's specific condition. ${ }^{5,24}$

\section{A methodological issue: the issue of response shift}

HRQoL assessment includes also the difficulties of comparing people because of varying standards for comparison as well as shifting standards over time. ${ }^{25}$ The issue of response shift refers to a phenomenon that can occur in any field where self-report data are collected and is an important methodological issue. The concept of response reflects the fact that patients make an assessment, judgment, or rating of a health state. The notion of shift implies change; more specifically a change in the patient's response. Response shift is a change in the meaning of one's self evaluation of a target construct as a result of a change in the respondent's internal standards of measurement or scale recalibration. Another reason is a redefinition of the target construct or concept redefinition or a change in the respondent's values or the importance of component domains representing the target construct. $^{12}$

While response shift is not new from a clinical perspective, it is a relatively new phenomenon from a methodological viewpoint. Assessments, completed over time may be incomparable due to shifting internal criteria values. ${ }^{11}$ Response shift describes changes in certain dimensions of HRQoL while other dimensions remain stable. Some measures of functioning are concrete and clearly defined, such as basic activities of daily living (for example someone can or can not walk up a flight of stairs) and are unlikely to undergo response shift. The factors that do undergo response shift with high susceptibility are general health perceptions and overall QoL, with a wide variety of determinants. ${ }^{26}$ Wilson (1999) reports that the more specific and discrete the concept being measured, the less the likelihood that response shift will occur. Respectively, the broader the concept measured, the more likely is that response shift will occur.

Conclusively, in case there is a change in health away from the homeostatic state, people immediately begin, in most cases, the process of response, readjustment and coping with short term or long term efforts. The concept of response shift potentially gives new insights into some uncomfortable clinical problems. ${ }^{26}$ Assessing response shift may therefore be needed to obtain a valid and sensitive assessment of change over time. Sprangers (2002) suggests that the most established method is the comparison of the baseline and retrospective measure that would provide a denotation of the amount and direction of response shift effects. ${ }^{11}$

\section{Factors associated with health related quality of life in chron- ic diseases}

There are a large number of publications that study HRQoL in chronic disease therefore the relatively recent ones (from 1997 to 2012) that cover a wide range of chronic diseases, were selected for the present study. In agreement with Wilson and Cleary model, factors that were found to be associated with poor and good HRQoL, will be presented.

\section{Factors associated with poor health related quality of life in cancer}

Richardson, Wingo, Zack, Zahran \& King (2008) examined HRQoL of breast cancer survivors between ages 20-64 and found that patients who reported being limited by cancer primarily and had unhealthy behaviours, showed lower HRQoL. ${ }^{27}$ HRQoL of breast cancer patients is associated with more limitations in activities of daily living especially in a great amount of patients aged 45-60 years (55\%) and 18-44 years old (39\%). ${ }^{28}$

Among factors that play an important role in HRQoL of breast cancer patients are psychosocial factors. Specifically, psychosocial factors such as problematic partner relationship, sexual functioning and body image as well as less adaptive coping strategies (e.g. lack of positive cognitive restructuring) were associated with impaired HRQoL. In addition patients under 50 years old were at risk for impaired HRQoL several years after diagnosis. ${ }^{29}$

Another factor found to have an influence in HRQoL of breast cancer patients is the type of surgery. Oshumi et al., (2009) found mastectomy surgery, to be associated with worse HRQoL than breast conserving treatment. ${ }^{30}$ Therefore, Montazeri (2008) presented an extensive bibliographic review (between 1974 and 2007) of breast cancer publications and concluded that treatment related side-effects negatively affect HRQoL and adherences to therapy. ${ }^{31}$

A type of cancer with survival rate at approximately $50 \%$ is head and neck cancer. Llewellyn, McGurk \& Weinman, (2005) under- 
took a systematic literature review and focused on psychosocial and behavioural factors. They concluded that lack of social support and satisfaction with information, depressive symptoms and behavioural factors (alcohol, smoking abuse) are associated with impaired HRQoL. ${ }^{32}$

\section{Heart diseases and stroke}

A number of publications, study HRQoL in patients with heart failure. Patients with heart failure have significant impairment of all aspects of HRQoL, not simply physical functioning. ${ }^{33}$ The physical (role and functioning) health burden is significantly greater than that suffered in other serious common chronic disorders, whether cardiac or other systems. Patients with heart failure that underwent a Left Ventricular Assist Device (LVAD) in situ, showed poorer HRQoL and psychological functioning compared to transplanted and explanted patients. A LVAD is an acceptable alternative therapy in selected patients who are not candidates for cardiac transplantation. More importantly, HRQoL is a predictor of mortality and morbidity after cardiac procedures. Presence of symptoms, such as chest pain, fatigue, and shortness of breath affect HRQoL when patients recover acute cardiac events or procedures (Table 1). ${ }^{33}$

Moreover, in coronary artery disease (CAD) patients, depressive symptoms and type D personality are independent predictors of poor HRQoL. People who show type D personality, experience negative emotions and inhibit the expression of emotion/behaviour. ${ }^{34}$ Type D personality is associated with vulnerability to chronic emotional distress and an increased risk for cardiac events in patients with CAD. ${ }^{34}$ Subjective (perceived) cognitive impairment in CAD patients is associated with poor HRQoL. ${ }^{35}$ While, neurocognitive functioning 5 years after coronary artery bypass grafting (CABG), is found to have a strong connection with decreased HRQoL. ${ }^{36}$

There are a number of papers that study HRQoL in stroke. Their findings suggest that factors such as hemispheral localization of the lesion, paresis, coordination disturbances and especially subjective tendency to depression are highly correlated with poor HRQoL. ${ }^{37}$ In addition, poststroke disability is a stronger predictor of low HRQoL than depression 1 year after stroke with patients with severe/moderate disability to have lower HRQoL than depressed patients. ${ }^{38}$ Handicap, anxiety, institutionalization and dementia are independently associated with HRQoL. Other investigators reported that cognition is an important factor that influences HRQoL. ${ }^{39}$ Finally, self-care and self-efficacy (the confidence a person has in his or her ability to perform relevant self-care activities) are related to HRQoL and depression after stroke. ${ }^{40}$

In primary care practice, insomnia seems to be one common complaint in patients with chronic diseases and has been associated with decline in physical and psychological health as well as increased mortality. Insomnia is found to be independently associated with worsened HRQoL to almost the same extent as chronic conditions such as congestive heart failure and clinical depression. ${ }^{41}$

\section{Diabetes, hepatitis C, HIV}

Among a variety of chronic diseases (Table 1), poor HRQoL is associated with a number of factors such as coexisting chronic diseases, with greater number coexisting chronic diseases a person has the more likely to report impaired HRQoL. ${ }^{42,43}$ Adverse health risk behaviours like smoking, obesity, physical inactivity and heavy drinking are associated with decreased HRQoL in patients with asthma and diabetes. $^{44}$ Additionally, in diabetes having multiple complications is clearly associated with decreased HRQoL. ${ }^{45}$

Depressive symptoms in hepatitis C patients were found to be connected to poor HRQoL. ${ }^{46}$ In HIV, individuals with asymptomatic HIV disease enjoy a physical HRQoL similar to that of their non infected counterparts. In contrast, emotional well-being is considerably worse for those with HIV infection than for those without HIV or with other chronic diseases. HRQoL had the strongest association with suicidal ideation among psychiatric patients with HIV and can potentially serve as a screening variable to identify patients particularly at risk. ${ }^{47}$

\section{Bowel disease, renal disease, multi- ple sclerosis}

Continuing, other factors that were found to be connected with poor HRQOL are symptomatic activity and the need for hospitalization in inflammatory bowel disease. ${ }^{48}$ Sociodemographic variables, like being female, older, less educated and divorced/widowed, are related to poor HRQoL in patients with end-stage renal disease (kidney function $5-10 \%$ of capacity). Women report lower psychological health, a more negative perception on different aspects of their environment and a stronger dissatisfaction with their finances and opportunities for recreation and acquiring new skills. ${ }^{49}$ Finally, subjective (perceived) cognitive impairment in multiple sclerosis (MS) was found to be connected with poor HRQoL. ${ }^{50}$

\section{Transplanted patients}

Kidney transplanted patients: end-stage renal patients undergo kidney transplantation and they are the vast majority of transplanted patients. The HRQoL of these patients is similar to that of the general population and higher than that of haemodialysis patients. However gender and educational level influence HRQoL, meaning that females and people with lower educational level show impaired HRQoL. ${ }^{51}$

Kidney, liver and heart transplanted patients: overall, transplanted patients, show satisfactory HRQoL with no differences in experienced HRQoL, 2 years after transplantation between kidney, liver, and heart transplant recipients. However, fifty-three percent of all patients reported bodily pain to be an important problem after organ transplantation, affecting daily living and it limits physical function, vitality and general health. ${ }^{52}$

\section{Factors associated with good \\ health related quality of life}

Alongside, there are some factors that were found to be associated with improved HRQoL. Among these seems to be heart revascularization especially in CAD elderly patients. Elderly patients that undergo cardiac surgery, benefit from improved functional status and HRQoL..$^{53}$ Many longitudinal studies have confirmed that HRQoL is generally improved after cardiac surgery, but most are restricted to short-term follow-up, although some studies have followed up patients at three, five and 20 years after surgery. ${ }^{53}$ Herlitz et al. (2009) conducted a study with long- term follow up and found that despite an ongoing decline in HRQoL over the years, there is still an improvement in most its aspects 15 years after CABG compared with that before surgery. Intensified early treatment of diabetes, obesity and left ventricular dysfunction in CABG patients might allow an even better long-term HRQoL. ${ }^{54} \mathrm{HRQOL}$ is reported to be a predictor of mortality following CABG. The use of an LVAD in patients with advanced heart failure resulted in a clinically meaningful survival benefit and an improved HRQoL. ${ }^{55}$

Oshumi et al., (2009) found that breast conserving treatment versus mastectomy in addition with younger age and higher education, are associated with slightly better HRQoL in breast cancer patients. Montazeri, (2008) suggests that interventions in these patients have a positive effect to HRQoL, despite the negative effects of the disease. ${ }^{30,31}$

Recent findings in diabetes, suggest that pump therapy, compared to multiple daily injections, has beneficial effects on HRQoL. While, results from large studies further suggest that intensive treatment itself does not impair HRQoL. In chronic diseases self-care management has been used as the theoretical underpinning for improved HRQoL. ${ }^{45}$

Patients with Chronic Kindey Disease (CKD) show a significant improvement in HRQoL after initiation of epoetin treatment in dialysis and early renal failure patients. The objective of epoetin treatment is a stable increase of haematocrit of four or more points above baseline. In addition HRQoL seems to have a strong positive correlation with haemoglobin concentration/haematocrit, higher 
Table 1. Studies associated with poor health related quality of life in chronic disease.

\begin{tabular}{|c|c|c|c|}
\hline Studies & Studied chronic disease & Participants & Results \\
\hline $\begin{array}{l}\text { Thommasen \& } \\
\text { Zhang, } 2006\end{array}$ & $\begin{array}{l}\text { Diabetes, hypertension, } \\
\text { hyperlipidemia, } \\
\text { depression/anxiety }\end{array}$ & 675 & $\begin{array}{l}\text { Coexisting chronic disease leads } \\
\text { to poor HRQoL }\end{array}$ \\
\hline Strine et al., 2008 & $\begin{array}{l}\text { Asthma, arthritis, diabetes, } \\
\text { heart disease }\end{array}$ & 13.483 & $\begin{array}{l}\text { Adverse health risk behaviours } \\
\text { (smoking, obesity, physical } \\
\text { inactivity, and heavy drinking) } \\
\text { lead to poor HRQoL }\end{array}$ \\
\hline $\begin{array}{l}\text { Katz \& } \\
\text { McHorney, } 2002\end{array}$ & $\begin{array}{l}\text { Hypertension, diabetes, } \\
\text { congestive heart failure, recent } \\
\text { myocardial infarction, depression }\end{array}$ & 3.445 & $\begin{array}{l}\text { Insomnia is associated with } \\
\text { worsened HRQoL }\end{array}$ \\
\hline Falasca et al., 2009 & Hepatitis C patients & 20 & $\begin{array}{l}\text { Depressive symptoms are } \\
\text { associated with poor HRQoL }\end{array}$ \\
\hline Haller \& Miles, 2003 & HIV psychiatric patients & 190 & $\begin{array}{l}\text { Suicidality has an association } \\
\text { with poor HRQoL }\end{array}$ \\
\hline Casellas et al., 2002 & Inflammatory bowel disease & 354 & $\begin{array}{l}\text { Symptomatic activity and theneed for } \\
\text { hospitalization are associated } \\
\text { with poor HRQoL }\end{array}$ \\
\hline Vinck et al., 1997 & $\begin{array}{l}\text { Multiple sclerosis, coronary } \\
\text { artery disease }\end{array}$ & 18 & $\begin{array}{l}\text { Subjective (perceived) cognitive } \\
\text { impairment is associated with } \\
\text { poor HRQoL }\end{array}$ \\
\hline Newman et al., 2001 & $\begin{array}{l}\text { Postoperative coronary } \\
\text { artery bypass grafting }\end{array}$ & 261 & $\begin{array}{l}\text { Neurocognitive functioning is } \\
\text { associated with poor HRQoL }\end{array}$ \\
\hline Denollet et al., 2000 & Coronary artery disease & 319 & $\begin{array}{l}\text { Symptoms of depression and } \\
\text { type D personality are associated } \\
\text { with poor HRQoL }\end{array}$ \\
\hline Theofilou 2011 & Renal disease (end-stage) & 144 & $\begin{array}{l}\text { Sociodemographic variables, } \\
\text { (female, older, less educated } \\
\text { \&divorced/widowed) are associated } \\
\text { with poor HRQoL }\end{array}$ \\
\hline Carod-Artal et al., 2000 & Stroke patients & 90 & $\begin{array}{l}\text { Poststroke disability is associated } \\
\text { with poor HRQoL }\end{array}$ \\
\hline Rebollo et al., 2000 & $\begin{array}{l}\text { Kidney transplanted patients } \\
\& \text { haemodialysis patients }\end{array}$ & $\begin{array}{l}210 \\
170\end{array}$ & $\begin{array}{l}\text { Sociodemographic variables } \\
\text { (females \& people with lower } \\
\text { educational level) are associated } \\
\text { with poor HRQoL }\end{array}$ \\
\hline Forsberg et al., 1999 & $\begin{array}{l}\text { Kidney, liver \& } \\
\text { heart transplanted patients }\end{array}$ & 76 & Bodily pain affects HRQoL \\
\hline
\end{tabular}

HRQDL, health related quality of life.

Table 2. Studies associated with good health related quality of life in chronic disease.

\begin{tabular}{|c|c|c|c|}
\hline Studies & Studied chronic disease & Participants & Results \\
\hline Adegbola, 2007 & $\begin{array}{l}\text { Renal disease, } \\
\text { fibromyalgia, AIDS, } \\
\text { arthritis, heart disease }\end{array}$ & 545 & $\begin{array}{l}\text { Spirituality is associated } \\
\text { with good HRQoL }\end{array}$ \\
\hline Rose et al., 2001 & $\begin{array}{l}\text { End-stage heart failure, } \\
\text { (left ventricular assist device surgery) }\end{array}$ & 129 & $\begin{array}{l}\text { Psychological functioning is } \\
\text { associated with good HRQoL }\end{array}$ \\
\hline Azzopardi, 2009 & Coronary artery disease & 48 & $\begin{array}{l}\text { Coronary Artery Bypass Grafting } \\
\text { is associated with good HRQoL }\end{array}$ \\
\hline Herlitz et al., 2009 & Coronary artery disease & 808 & $\begin{array}{l}\text { Early treatment of diabetes, } \\
\text { obesity \& left ventricular } \\
\text { dysfunction are associated } \\
\text { with good HRQoL }\end{array}$ \\
\hline Oshumi et al., 2009 & Breast cancer & 100 & $\begin{array}{l}\text { Breast Conserving Treatment, } \\
\text { younger age \& higher education } \\
\text { are associated with good HRQoL }\end{array}$ \\
\hline
\end{tabular}


socioeconomic level and level of education. ${ }^{56}$

People with chronic illness have identified spirituality as a resource that promotes HRQoL. Spirituality is described as an important element of life, invades all areas of life, enables the person to cope and make sense of the current situation and is studied by few authors and researchers. Spiritual care is a valid part of healthcare delivery and health care professionals should provide spiritual care. $^{57}$ Issues of healthcare and spirituality have a common meeting place in suffering from chronic disease, because both offer deliverance and healing in varying degrees. Spirituality plays an important role in reduction of suffering well-being and enhancement of HRQoL is evident among all people and needs explanation beyond the usual ethnocentric perspective (Table 2). ${ }^{57}$

\section{Chronic diseases with impact on health related quality of life}

In addition to factors that were found to be associated with poor and good HRQoL, there is the question of which chronic diseases mostly affect HRQoL, according to the literature. Depression is found to be the most disabling disease and osteoarthritis of the knee had greater impact on the HRQoL than many other chronic diseases, in Chinese patients..$^{58,59}$ On the other hand, patients in Europe, who reported the poorest levels of functioning, were those with cerebrovascular/neurologic conditions, renal disease and musculoskeletal conditions, something that raises cross-cultural differences issues. ${ }^{60}$

Cross-cultural differences represent the differences between cultures about health and diseases. Different cultures define health with different ways and tend to focus in different health behaviours. The chronic diseases that mostly affect HRQoL according to Asian population are not the same compared to Western population because Asian population perceive health with more holistic way. Although a major number of studies are referred to North America population, there are studies that investigate HRQoL of other cultures, too. ${ }^{58,59,61}$

In contrast, symptomatic activity and sociodemographic variables such as gender and education, male with higher level of education and inactive disease, showed better HRQoL in patients with inflammatory bowel disease. ${ }^{48}$ Additionally, urogenital conditions, hearing impairments, psychiatric disorders, and dermatologic conditions were found to result in relatively favourable functioning. ${ }^{60}$

Consequently, HRQoL assessment is used as an outcome of any therapeutic intervention, particularly when invasive procedures such as cardiac operations are performed on groups with limited life expectancy. ${ }^{62}$ Measures of functioning, morbidity, and mortality do not provide complete information about physical, functional, emotional, and mental well-being and can be supplemented by the patient's perceptions of their recovery. ${ }^{54}$

\section{Interventions for chronic diseases}

The research of HRQoL in chronic disease is necessary for the creation of interventions. Factors that were found to be associated with good HRQoL in chronic diseases could be used for the design of intervention programmes. Interventions would strengthen public health actions to manage chronic disease. ${ }^{18}$ Health interventions are very useful for the patients with different chronic diseases and medical staff too and could become medical routine in the daily care of such patients.

Interventions may include different programmes for different chronic disease. A main contribution of the medical interventions is in decision making, especially in patients with cancer. Intervention studies include physical training, relaxation training, health education and stress management programmes, very useful for CAD patients. ${ }^{63}$ Minimal interventions, with educational self-management skills can help patients to reduce the stigmatization related with specific diseases such as HIV and cancer. Other programmes provide psychosocial counselling and health education too ${ }^{63}$

Psychological assessment and interventions to reduce psychological morbidity and improve HRQoL will be important in patients with heart failure, particularly in view of the increasing numbers of LVADs being implanted and the possibility of their use for long-term destination therapy. ${ }^{64}$ Given the dramatic decline in HRQoL, heart failure healthcare interventions will improve it. ${ }^{65}$ Studies show that patients are satisfied with their HRQoL at 1 month after implantation of a LVAD and are optimistic about how well they thought they would do after heart transplantation. Psychological factors are considered to be the strongest predictors of satisfaction with overall QoL. ${ }^{66}$

In addition, as regards enhancement of HRQoL, one intervention that used to enhance HRQoL is palliative care. Palliative care provides the patient with life enhancing (rather than life sustaining) interventions in an effort to improve HRQoL. Palliative care focuses on patients whose disease is not responsive to curative treatment and includes control of pain, other symptoms, as well as psychological, social and spiritual problems. ${ }^{67}$ The ultimate goal of palliative care is the best HRQoL possible and can be implemented at any point along the chronic illness trajectory and is compatible with active medical care. ${ }^{68}$

Other interventions that may improve HRQoL include support and encouragement strategies, patient education, exercise programs, employment support and active selfmanagement. ${ }^{69}$ It is however useful, within the same chronic disease, to compare people at the same stage of the disease, as each disease has its own usual trajectory. Jenkins (1992) states that trajectories of HRQoL may vary between diseases and are characterized as a function of the balance between forces for improvement and for decline in the disease and in the individual including their age, social characteristics, general health and psycho- social wellbeing. ${ }^{70}$

Besides all these, there are evidence-based interventions aimed at preventing chronic disease (as ending smoking, eating healthy food and limiting weight gain). These interventions need to be studied in people with one or more diseases to assess their effectiveness. ${ }^{?}$

\section{Discussion}

In sum, QoL is inherently a dynamic, multilevel and complex concept, reflecting objective, subjective, macro-societal and micro-individual, positive and negative influences which interact. ${ }^{71}$ HRQoL is a multidimensional construct that consists of least three broad domains - physical, psychological, and social functioning - that are affected by one's disease and/or treatment. ${ }^{11}$ Most studies in people with various chronic conditions, usually are describing HRQoL and it would be unusual to see the broader aspects of QoL included/evaluated.

Measuring HRQoL without reference to a conceptual model has constrained the development of a knowledge base for HRQOL research. A conceptual model places concepts in a context and guides the development of new theories. Using theoretically based conceptual models will enhance the applicability of the concept as a reliable and valid outcome measure. $^{72}$

The aforementioned Wilson and Cleary HRQoL conceptual model (1995) provides a theoretical approach to conceptualizing HRQoL as a multidimensional construct and could be used to unify the biomedical and social science paradigms. The biomedical paradigm focuses on pathological processes and biological, physiological, and clinical outcomes, while the social science paradigm focuses on functioning and overall wellbeing. ${ }^{12}$ This model could be used as a tool to assess interventions and organizational performance within the new view that emphasizes health, functioning and QoL and focuses on health care. It guides to the development of new theories, could be used as a tool to assess interventions and identify measure and improve quality care for health care providers and appropriate patient outcomes that contribute to a better quality patient care. ${ }^{13}$ It thereby, challenges researchers and clinicians to be responsible for the consequences of their 
actions in response to changing roles and perceptions about what constitutes HRQoL. ${ }^{13}$

In general, research on patients with various chronic diseases indicates that coexisting chronic diseases, adverse health risk behaviours, depressive symptoms, insomnia and cognitive impairment, are associated with impaired HRQoL. Therefore, intensified early treatment of diabetes, obesity, and left ventricular dysfunction, spirituality and interventions for reducing psychological morbidity are associated with improved HRQoL.

It seems difficult to get a coherent view of the relationship between HRQoL and chronic disease when the conditions are varying as well as the ethnic and cultural background of the population studied. The studies mentioned earlier (Tables 1 and 2) have several limitations, are heterogeneous some of them have a small number of participants and the studied patients are in different stages of different diseases. However, these studies provide with very useful findings available for testing in future research.

The estimation of the relative impact of chronic diseases on HRQoL is necessary to better plan and distribution resources for research, training and health care, to further promote living well with chronic diseases. Consequently, collaboration among different sciences could produce better treatment outcomes for people living with chronic disease, especially those who are in greatest need. An integrated framework, such as the biopscychosocial model, for healthcare would be built on a single guiding principle: that the aim of addressing the physical, social and psychological aspects of chronic disease is to help patients with chronic diseases and the whole population, to live well, regardless of the chronic disease or an individual's own current state of health. ${ }^{60}$

Bowling et al. (2003) suggest that, research on peoples' values, shows that people within a society do share a common set of core values, although these vary in their relative importance to individuals and different social groups. People's values include the meeting of past expectations, coping ability, independence and control, health, relationships with others, work, finances and standard of living and leisure activities. An important health care objective enhances all these and contribute to the increase of life span years, while maintaining an optimal HRQoL something that is not only a primary concern of patients, their families and clinicians, but is also of global policy interest. ${ }^{17}$

HRQoL is a very useful construct with broader domains that can be used to provide the scientific community with the tools for patientcentred health care. Integrated patient treatment should include a lot of specialties besides physicians like psychologies, nurses and social workers in order to achieve the enhancement of HRQoL in patients with chronic disease.

\section{References}

1. World Health Organisation. The first ten years. The health organization. Geneva: World Health Organisation; 1958

2. World Health Organisation. Programme on mental health. Geneva: World Health Organisation; 1996.

3. Meeberg GA. Quality of life: a concept analysis. J Adv Nurs 1993;18:32-8.

4. Hiatt JF. Spirituality, medicine, and healing. South Med J 1986;79:736-43.

5. Cella D, Nowinski CJ. Measuring quality of life in chronic illness: the functional assessment of chronic illness therapy measurement system. Arch Phys Med Rehabil 2002;83(Suppl. 2):10-7.

6. Patrick DL, Erickson P. Health status and health policy: quality of life in health care evaluation and resource allocation. New York: Oxford University Press; 1993.

7. Brown J, Bowling A, Flynn T. Models of quality of life: a taxonomy, overview and systematic review of the literature. Proceedings of European Forum on Population Ageing Research. Sheffield, UK; June 2004.

8. Sevinc S, Akyol AD. Cardiac risk factors and quality of life in patients with coronary artery disease. J Clin Nurs 2010;19:1315-25.

9. Ziller RC. Self-other orientation and quality of life. Soc Indic Res 1974;1:301-27.

10. Staquet MJ, Hays RD, Fayers PM. Quality of life assessment in clinical trials. New York: Oxford University Press; 1998.

11. Sprangers MA. Quality-of-life assessment in oncology. Achievements and challenges. Acta Oncol 2002;41:229-37.

12. Wilson IB, Cleary PD. Linking clinical variables with health-related quality of life: a conceptual model of patient outcomes. J Am Med Assoc 1995;273:59-65.

13. Sousa KH, Kwok OM. Putting Wilson and Cleary to the test: analysis of a HRQOL conceptual model using structural equation modelling. Qual Life Res 2006;15:725-37.

14. Ferrans CA, Zerwic JJ, Wilbur JE, Larson JL. Conceptual model of health-related quality of life. J Nurs Scholars 2005;37:336-42.

15. Zautra A, Hempel A. Subjective well-being and physical health: a narrative literature review with suggestions for future research. Int J Aging Hum Dev 1984;19:95-110.

16. Bowling A, Bannister D, Sutton S. A multidimensional model of QoL in older age. Aging Ment Health 2002;6:355-71.

17. Bowling A, Gabriel Z, Dykes J, et al. Let's ask them: a national survey of definitions of quality of life and its enhancement among people aged 65 and over. Int J Aging Hum
Dev 2003;56:269-306.

18. Devins GM, Blinik YM, Hutchinson TA, et al. The emotional impact of end-stage renal disease: Importance of patients' perceptions of intrusiveness and control. Int J Psychiatry Med 1983;13:327-43.

19. Blalock SJ, De Vellis BM, De Vellis RF. Adjustment to rheumatoid arthritis: the role of social comparison processes. Health Educ Res 1990;5:361-70.

20. Blalock SJ, De Vellis BM, De Vellis RF. Social comparison among individuals with rheumatoid arthritis. J Appl Soc Psychol 1989;19:665-80.

21. Ware JE, Snow KK, Kosinski M, Gandek B. SF-36 health survey manual and interpretation guide. Boston: New England, Medical Center; 1993.

22. Hunt $S$, McKenna S. The Nottingham Health Profile user's manual. Manchester: Galen Research and Consultancy; 1991.

23. The EuroQol group. EuroQol - a new facility for the measurement of health related quality of life. Health Policy 1990;16:199-08.

24. Cella DF, Tulsky DS, Cray G, et al. The functional assessment of cancer therapy scale: development and validation of the general measure. J Clin Oncol 1993;11:570-9.

25. Sprangers M, Schwartz CE. Integrating response shift into health-related quality of life research: a theoretical model. Soc Sci Med 1999;48:1507-15.

26. Wilson I. Clinical understanding and clinical implications of response shift. Soc Sci Med 1999;48:1577-88.

27. Richardson LC, Wingo PA, Zack MM, et al. Health related quality of life in cancer survivors between ages 20 and 64 years. Cancer 2008;112:1380-9.

28. Hewitt M, Rowland JH, Yancik R. Cancer survivors in the United states: age, health and disability. J Gerontol A Biol Sci Med Sci 2003;58:M82-91.

29. Avis NE, Crawford S, Manuel J. Quality of life among younger women with breast cancer. J Clin Oncol 2005;23:3322-30.

30. Oshumi S, Shimosuma K, Morita S, et al. Factors associated with Health related quality of life in breast cancer survivors: influence of the type of the surgery. Jpn J Clin Oncol 2009;39:491-6.

31. Montazeri A. Health-related quality of life in breast cancer patients: a bibliographic review of the literature from 1974 to 2007. J Exp Clin Cancer Res 2008;27:1-31.

32. Llewellyn CD, McGurk M, Weinman, L. Are psycho-social and behavioural factors related to health related-quality of life in patients with head and neck cancer? A systematic review. Oral Oncol 2005;41:440-54.

33. Fukuota Y, Lindgren T, Rankin S, et al. Cluster analysis: a useful technique to identify elderly cardiac patients at risk for poor quality of life. Qual Life Res 2007;16:1655- 
63.

34. Denollet J, Vaes J, Brutsaert DL. Inadequate response to treatment in coronary heart disease. Adverse effects of type D personality and younger age on 5-year prognosis and quality of life. Circulation 2000;102:630-5.

35. Kiessling A, Henriksson P. Perceived cognitive function is a major determinant of health related quality of life in a non-selected population of patients with coronary artery disease - a principal components analysis. Qual Life Res 2004;13:1621-31.

36. Newman MF, Grocott HP, Mathew JP, et al. Report of the substudy assessing the impact of neurocognitive function on quality of life 5 years after cardiac surgery. Editorial Comment. Stroke 2001;32:2874-81

37. Niemi ML, Laaksonen R, Kotila M, Waltimo 0. Quality of Life 4 years after stroke. Stroke 1988;19:1101-7

38. Carod-Artal J, Egido JA, González JL, de Seijas E. V. Quality of Life among stroke survivors evaluated 1 year after stroke: experience of a Stroke Unit. Stroke 2000;31:29953000.

39. Clarke PJ, Black S, Badley E, et al. Handicap in stroke survivors. Disabil Rehabil 1999;21:116-23.

40. Robinson-Smith G, Johnston MV, Allen J. Self-care self-efficacy, quality of life, and depression after stroke. Arch Phys Med Rehabil 2000;81:460-4.

41. Katz DA, McHorney C. A. The Relationship between insomnia and health-related quality of life in patients with chronic illness. $\mathrm{J}$ Fam Pract 2002;51:229-35.

42. Thommasen HV, Zhang W. Impact of chronic disease on quality of life in Bella Coola Valley. Rural Remote Health 2006;6:1-18.

43. Adams RJ, Wilson DH, Taylor AW, et al. coexistent chronic conditions and asthma quality of life: a population-based study. Chest 2006;129:285-91.

44. Strine TW, Chapman DP, Balluz LS, et al. The associations between life satisfaction and health-related quality of life, chronic Illness, and health behaviors among U.S. community-dwelling adults. J Commun Health 2008;33;40-50.

45. Pouwer F, Hermanns N. Insulin therapy and quality of life. A review. Diabetes Metab Res Rev 2009;25:4-10.

46. Falasca K, Mancino P, Ucciferri C, et al. Quality of life, depression, and cytokine patterns in patients with chronic hepatitis $\mathrm{C}$ treated with antiviral therapy. Clin Invest
Med 2009;32:E212-18.

47. Haller DL, Miles DR. Suicidal ideation among psychiatric patients with HIV: psychiatric morbidity and quality of life. AIDS Behav 2003;7:101-8.

48. Casellas F, Lopez-Vivancos J, Casado A, Malagelada JR. Factors affecting health related quality of life of patients with inflammatory bowel disease. Qual Life Res 2002;11:775-81.

49. Theofilou P. The role of sociodemographic factors in health - related quality of life of patients with end - stage renal disease. Int $\mathbf{J}$ Caring Sci 2011;4:40-50.

50. Vinck J, Put C, Arickx M, Medaer R. Objective and subjective cognitive dysfunction and quality of life in multiple sclerosis. Int J Rehabil Health 1997;3:187-95.

51. Rebollo P, Ortega F, Baltar JM, et al. Health related quality of life (HRQOL) of kidney transplanted patients: variables that influence it. Clin Transplant 2000;14:199-207.

52. Forsberg A, Lorenzon U, Nilsson F, Bäckmana L. Pain and health related quality of life after heart, kidney, and liver transplantation. Clin Transplant 1999;13:453-60.

53. Azzopardi S, Lee G. Health-related quality of life 2 years after coronary artery bypass graft surgery. J Cardiovasc Nurs 2009;24:232-40.

54. Herlitz J, Brandrup-Wognsen G, Evander MH, et al. Quality of life 15 years after coronary artery bypass grafting. Coron Artery Dis 2009;20:363-9.

55. Rose EA, Gelijns AC, Moscowitz AJ, et al. Long term use of a left ventricular assist device for end-stage heart failure. New Engl J Med 2001;345:1435-43.

56. Valderrabano F. Quality of life benefits of early anaemia treatment. Nephrol Dial Transplant 2000;15 (Suppl 3):23-8.

57. Adegbola M. Spirituality and quality of life in chronic illness. J Theor Construction Testing 2007;10:42-6.

58. Cheung JC, Kwan AY, Chan SS, et al. Quality of life of older adults: benefits from caring services in Hong Kong. Soc Indic Res 2005;71:291-334.

59. Lam C, Lauder I. The impact of chronic diseases on the health-related quality of life (HRQOL) of Chinese patients in primary care. Fam Pract 2000;17:159-66.

60. Sprangers M, de Regt E, Andries F, et al., Which chronic conditions are associated with better or poorer quality of life? J Clin Epidemiol 2000;53:895-907.

61. Magaji BE, Moy FM, Roslani AC, et al. Health related quality of life among colorectal cancer patients in Malaysia: a study protocol. BMC Cancer 2012;12:1-6.

62. Fruitman DS, MacDougall CE, Ross DB. Cardiac surgery in octogenarians: can elderly patients benefit? Quality of life after cardiac surgery. Ann Thorac Surg 1999;68:2129-235.

63. van Elderen, T. Quality of life in patients with cancer, CNSLD, coronary heart disease and diabetes mellitus: a review of research in the Netherlands. In: Rodriguez-Martin J, ed. Health psychology and quality of life research. Alicante: University of Alicante: 1995.

64. Wray J, Hallas CN, Banner NR. Quality of life and psychological well-being during and after left ventricular assist device support. Clin Transplant 2007;21:622-7.

65. Hobbs FDR, Kenkre JE, Roalfe AK, et al. Impact of heart failure and left ventricular systolic dysfunction on quality of life. A cross-sectional study comparing common chronic cardiac and medical disorders and a representative adult population. Eur Heart J 2002;23:1867-76.

66. Grady KL, Meyer P, Mattea A, et al. Predictors of quality of life at 1 month after implantation of a left ventricular assist device. Am J Crit Care 2002;11:345-52.

67. World Health Organization. Cancer pain relief and palliative care (Technical report series 804). Geneva: World Health Organization; 1990.

68. Jablonski A. Level of symptom relief and the need for palliative care in the hemodialysis population. J Hospice Palliative Nurs 2007;9:50-60.

69. Molzahn AE. Quality of life and chronic kidney disease: living long and living well. In: Molzahn A, ed. Contemporary nephrology nursing: principles and practice. 2nd ed. Pitman, NJ: Anthony J. Jannetti; 2006. pp 345-355.

70. Jenkins CD. Assessment of outcomes of health interventions. Soc Sci Med 1992;35;367-75.

71. Lawton MP. A multidimensional view of quality of life in frail elders. In: Birren JE, Lubben J, Rowe J, Deutchman D, eds. The concept and measurement of quality of life. New York: New Academic Press; 1991.

72. Fawcett J, Downs FS. The relationship of theory and research. Philadelphia: FA Davis; 1992. 